\title{
Bovine Trypanosomiasis Epidemiology and Tsetse Fly Density in Jimma Arjo District, East Wollega Zone, Oromia Regional State, Ethiopia
}

\author{
Debela Abdeta Efa (ID \\ School of Veterinary Medicine, Wollega \\ University, Nekemte, Ethiopia
}

Background: Bovine trypanosomosis remains a vital livestock disease and constraint which is intimidating livestock health and production, regardless of ongoing tsetse and trypanosomosis control struggles in Jimma Arjo district, East Wollega zone, Ethiopia.

Methods: A cross-sectional study was carried out with the objective of determining prevalence of cattle trypanosomiasis and apparent tsetse fly density in six randomly selected peasant associations of Jimma Arjo District from April 2018 to January 2019.

Results: From overall 819 arbitrarily selected cattle $(n=36 ; 4.39 \%)$, infection rate was recorded. Selected animals were invariably infested with different trypanosome species among which Tryapanosoma congolense (80.55\%) was the most common, followed by T. vivax $(11.11 \%), \quad T$. brucei $(5.55 \%)$ respectively. Co-infection of $T$. vivax and T. congolense accounted for $2.77 \%$ of total infection rate. This finding indicates a statistically significant difference $(\mathrm{p}<0.05)$ among good, medium, and poor body condition animals with respect to Tryapanosomosis infection rate. Poor body condition animals were highly infected with trypanosome parasite as compared to medium and good body condition score animals. This study shows statistically significant association was obtained between mean packed cell volume $(\mathrm{PCV})$ and trypanosomiasis infection rate $(\mathrm{P}<0.05)$. The lower mean PCV value $(21.14 \%)$ were highly affected as compared with high mean PCV value animals $(25.26 \%)$. The result of entomological survey, by using mono pyramidal traps deployed near animal grazing field and rivers of selected peasant association (PA), showed presence of four Glossina species namely Glossina morsitans, G. pallidipes, G. tachinoides, and G. fuscipes with high fly density per trap in Meta PA. Higher catches of G. fuscipes were registered as compared to other vectors.

Conclusion: Generally, this study indicated the disease is still a main problem for livestock health and production in the study area and it necessitates disease and tsetse fly control.

Keywords: bovine trypanosomiasis, buffy coat, Jimma Arjo, prevalence, tsetse flies

\section{Introduction}

For the vast majority of African people, livestock is their mainstay. It contributes a huge percentage of the continents' GDP. Livestock also constitutes a major source of foreign currency earning for a number of African and other continents/countries. Production of livestock, indeed, contributes to improve food security and poverty alleviation in the developing world. Ethiopia is one of the countries with huge and diverse livestock population that plays an important role in the livelihoods of farmers, pastoralists, and economies of the country at large. For these reasons,
Correspondence: Debela Abdeta Efa School of Veterinary Medicine, Wollega University, Nekemte, Ethiopia

Tel +251913125925

Email debela.abdeta@gmail.com 
they are a "Living bank" or "Living account" for both rural and urban poor farmers or livestock owners. ${ }^{1}$

Ethiopia's economy is, to a large extent, reliant on crop and animal production. In addition to its direct contribution in terms of GDP and foreign exchange, cattle provides draught power for cultivation whereas equines are used for transportation of agricultural crops and people in rural parts of the country. ${ }^{2}$

African animal trypanosomiasis (AAT) caused by six trypanosomes species is a major animal health problem over a large area of tsetse belt region of the continent. In sub Saharan Africa, it jeopardizes the lives of around 55 million people. African animal trypanosomiasis is a chronic debilitating protozoan disease of livestock which greatly affects the economy of different countries. The vascular trypanosome namely $T$. vivax and T. congolense are the most pathogenic, economically significant, and extensively dispersed in Ethiopia. ${ }^{3}$

Trypanosome transmitted by Tsetse fly continues to be a major constraint in livestock production. It is also a major risk of infection in humans. The disease greatly affects social, economic, and agricultural development of communities in tsetse infested areas. ${ }^{4}$ The resistance of trypanosome to existing antitrypanosomal drugs, increasing vectors' resistance to insecticides, absence of effective vaccines, and adverse effects of existing antitrypanosomal drugs are challenges in controlling the disease. People have been using both plant and animal species for treatment and control of Trypanosomiasis and as tsetse fly repellent in Ethiopia. ${ }^{5-7}$

Eighty-eight percent (88\%) of human population and $70 \%$ livestock population exist in the highland area of Ethiopia. From the total land coverage of the country, $36.3 \%$ of it is highland which is heavily degraded and unable to provide enough food for the community living there. In contrast, low lands of the country that accounts for $63.7 \%$ of the total land coverage, supports about $12 \%$ of humans and $33 \%$ of livestock population. Tsetse and Trypanosomiasis threat have rendered these fertile lands inaccessible. The North West region is affected by tsetse and non-tsetse transmitted trypanosomiasis. ${ }^{8-10}$ In Ethiopia, tsetse fly vectors are limited to Western and Southern regions of the country between longitude $33^{\circ}$ and $38^{\circ} \mathrm{E}$ and latitude $5^{\circ}$ and $12^{\circ} \mathrm{N}$ infesting areas which together account for $97,855 \mathrm{Km}^{2} .{ }^{11,12}$

Tsetse fly vector found in Ethiopia are uneven and livestock interference is constantly increasing. Accordingly, additional areas are being infested and newly settled communities are being continually affected by the progressing tsetse. This progression of tsetse fly is commonly found in Ghibe Omo with its tributaries, upper Didessa valley, Rift Valley areas of north and north-eastern edge of Lake Abaya. ${ }^{13}$

Tsetse fly vector and Trypanosomiasis control schemes have become focused in particular areas of higher priority where control is technically feasible and economic returns are measurable. ${ }^{14}$ In an attempt to reduce this disease which is the bottleneck of the country's economy, it requires further up-to-date research on description of host, agent, and environment relationship in Jimma Arjo. The present research was initiated to assist in decision making to oversee suitable tsetse and Trypanosomiasis control strategy. The present study was therefore aimed at the following objectives:

- To determine the prevalence of cattle Trypanosomiasis in selected PA's of Jimma Arjo district.

- To measure the type and apparent density of vector tsetse flies and other mechanical vectors in the study area.

\section{Materials and Methods Ethical Approval}

Ahead of starting data collection, ethical clearance was obtained from research ethics committee of School of Veterinary Medicine, Wollega University dated 20/07/ 2017 with minute no. SVM.RERC/008. Data were collected after getting the permission from animal owners to collect samples from animals. During the course of data collection, information received was nameless, and confidentiality of data was secured.

\section{Study Area}

This study was conducted in Oromia regional state, Eastern Wollega Zone, Jimma Arjo District located at $50 \mathrm{Km}$ distance from Zonal city. According to the district's agricultural and rural development office, (2010) the climatic condition interchanges with winter dry seasons (from December to February), short rainy seasons (March and April) and long summer rain fall (from June- September). This study was conducted in 6 PAs, namely Badasa Didesa, Meta, Cafe Arjo, Jammo Giros, Hara Keku and Tuqa. The area has different vegetation type, livestock and Wild game such as crocodiles, hippos, buffalos, Kudu Bush pig, and warthog. 
Since the area has fertile land the community's livelihood mainly depends on agriculture with mixed farming system. Livestock production mainly acts as fundamental part of mixed livestock production and agricultural land farming system.

\section{Study Population}

Zebu cattle kept under extensive traditional husbandry form were included.

\section{Study Design}

Cross-sectional study design using simple random sampling method was employed to determine the prevalence of cattle trypanosomiasis. Baited traps with different fly attractants were deployed at an interval of 200 to 250 meters for entomological survey. ${ }^{15}$

\section{Sample Size Determination}

The total number of animals required for this study was determined using the formula given by Thrusfield. ${ }^{16}$

Required sample size $(\mathrm{N})=1.96^{2} *$ Expected Prevalence (1- P Expected Prevalence) $/ \mathrm{d}^{2}$

Where, $\mathrm{d}=$ desired absolute precision at $95 \%$ confidence level and 5\% absolute precision. Since there was no previous report from the same area 50\% expected prevalence was assumed. Though 384 had to be included 819 animals were examined to increase the precision.

\section{Study Method and Sample Collection Parasitological Survey}

Blood samples were collected into capillary tubes after piercing ear vein of the selected animal by lancet. One end of the capillary tube was closed by sealant; centrifuged at $12,000 \mathrm{rpm}$ for five minutes to separate blood cells and to concentrate trypanosome using centrifugal force. Then PCV was calculated using hematocrit reader. Anemia was estimated by comparing PCV in which they were considered anemic, if their $\mathrm{PCV}<24 .{ }^{17,18}$ Capillary tubes were then broken just below buffy coat and exposed on microscope slide and covered by cover slip of $22 \times 22 \mathrm{~mm}$. It was then observed under $40 \mathrm{X}$ objective using dark ground buffy coat technique to detect the existence of parasites. For positive samples Giemsa stain of thin blood films were made. ${ }^{19,20}$

\section{Entomological Survey}

To assess the apparent density and species of tsetse and other biting flies, 90 baited monopyramidal traps were deployed in different vegetation types at the side of river and woody grassland, ${ }^{21}$ fifteen each in selected PAs. Each trap was odor baited either with acetone, octanol or cow urine which attracts tsetse flies. The lower part of each trap stick was smeared with grease to prevent ants mounting up the stick toward the gathering cage to prevent tsetse fly damage in the cage. The trap was deployed for a total of 48 hours. After flies were captured in the collecting cage they were sorted and recorded by species, sex, and sites of collection were recorded. The flies captured per trap were counted, identified, and apparent fly density per trap $(\mathrm{f} / \mathrm{d} / \mathrm{t})$ was calculated by adding the total number of flies and dividing by the number of traps per day. ${ }^{15}$ Characteristic morphology was used for identification of sex of tsetse flies. Other biting flies were also separated according to their characteristic morphology such as color, size, proboscis and venation of the wing structures at the genus level. $^{22,23}$

\section{Data Management and Analysis}

For the analysis, collected data were entered into MS excel sheets and analyzed using SPSS version 20 software. Difference between different risk factors and disease status were assessed using Chi-squared test and two sample Student's $t$-test. Statistically significant difference among parameters was tested at probability levels of $\mathrm{P}<0.05$ and 95\% CI. Finally, the fly population was calculated according to ${ }^{15}$ by dividing the number of flies caught by the number of traps deployed and number of days of deployment and expressed as fly/trap/day.

\section{Results}

From 819 animals examined, 36 were found positive for bovine Trypanosomiasis with overall prevalence of $4.4 \%$ in the study area. This prevalence was determined to be 4.35\% in Badasa Didesa, 7.19\% in Meta, 3.94\% in Café Arjo, $1.86 \%$ in Jammo Giros, $8.19 \%$ in Hara Keku and $1.98 \%$ in Tuqa. Among those six peasant associations the highest prevalence rate was $8.19 \%$ in Hara Keku, the lowest being in Jammo Giros, 1.86\%. Table 1: summarizes prevalence of cattle trypanosomiasis in six selected PAs.

The prevalence of trypanosome infection in males and females was $5.3 \%$ and $3.04 \%$, respectively. The prevalence of the disease was higher in males than females $\left(\chi^{2}=2.4064\right.$; $\mathrm{P}>0.05$ ), though the association was not statistically significant.

Out of the sampled cattle, $24.8 \%, 51.9 \%$, and $23.3 \%$ were recorded as having poor, medium, and good body 
Table I Prevalence of Cattle Trypanosomiasis in PAs

\begin{tabular}{|l|l|l|l|l|l|}
\hline Peasant Association & Number of Examined Animals & Tested Positive & Prevalence Rate (\%) & $\chi^{2}$ & p-value \\
\hline Badasa Didesa & 115 & 5 & 4.35 & \\
Meta & 139 & 10 & 7.19 & \\
Cafe Arjo & 127 & 5 & 3.94 & \\
Jammo Giroos & 215 & 4 & 1.86 & 8.35 \\
Hara Keku & 122 & 10 & 8.19 & \\
Tuqa & 101 & 2 & 1.98 & \\
Total & 819 & 36 & 4.4 & \\
\end{tabular}

condition respectively. A higher prevalence rate, $4.94 \%$, was found in medium body condition animals followed by $4.71 \%$ prevalence rate in good body condition animals. The lowest infection rate, $2.95 \%$, was recorded in poor body condition animals. Table 2 summarizes association between BCS, age, and sex with their respective prevalence rate in selected PAs.

Table 3 summarizes the mean PCV of examined cattle in selected PAs.

Statistical test applied to evaluate the presence of association between disease and mean PCV value for the parasitemic cattle showed 21.14+5.45 SD while the mean PCV value for the aparasitemic cattle was $25.26+4.3 \mathrm{SD}$. There was a statistically significant difference $(p<0.05)$ in mean PCV value between parasitemic and aparasitemic cattle.

Three species of trypanosome were detected namely Trypanosoma congolense, T. vivax, T. brucei and mixed infection of $T$. congolense, $T$. vivax. From a total of 36 infected animals, $29(80.55 \%)$ were found to be infected with $T$. congolense. Therefore $T$. congolense was considered the predominant species responsible for infection of cattle living in selected PAs. The remaining, 4 (11.11\%), 2 (5.55\%), $1(2.77 \%)$ were found to be infected by $T$. vivax, T. brucei and mixed $T$. congolonse and $T$. vivax respectively.

\section{Entomological Finding}

Entomological survey indicated 1083 tsetse flies, 33 Stomoxys and 8 tabanus were trapped at selected PAs during study period. This shows the overall $6.01 \mathrm{f} / \mathrm{t} / \mathrm{d}$ apparent density of tsetse flies trapped. Four tsetse species have been identified. Three hundred and fifty six (32.87\%) G. f.fuscipes, 294 (27.15\%) G. pallidipes, and 237 $(21.88 \%) \quad G$. tachinoides and $196 \quad(18.1 \%)$

Table 2 Association Between Prevalence and Risk Factors

\begin{tabular}{|l|l|l|l|l|l|l|}
\hline Variables & Variable Classification & Non-Infected & Infected & Prevalence (\%) & $\chi^{2}$ & P-value \\
\hline BCS & Good & 182 & 9 & 4.7 & 1.35 & 0.510 \\
& Medium & 404 & 21 & 4.9 & \\
& Poor & 197 & 6 & 3.0 & \\
\hline \multirow{2}{*}{ Age } & $<2$ & 82 & 3 & 3.7 & 3.38 \\
& $2-5$ & 204 & 8 & 3.9 & 0.781 \\
& $>5$ & 533 & 25 & 4.7 & \\
\hline Sex & Male & 464 & 26 & 5.3 & 3.1 & \\
& Female & 319 & 10 & 3.1 & 0.121 \\
\hline
\end{tabular}

Table 3 The Mean PCV of Examined Cattle in Jimma Arjo District

\begin{tabular}{|l|l|l|l|}
\hline Result & Mean PCV & SD & 95\% Confidence Level \\
\hline Aparasitemic & 25.26 & 4.3 & $24.96-25.56$ \\
Parasitemic & 21.14 & 5.45 & $19.29-22.98$ \\
Total & 25.08 & 4.44 & $24.77-25.38$ \\
\hline
\end{tabular}


Table 4 The Mean Catch of Glossina Species in Selected PA of Jimma Arjo District

\begin{tabular}{|c|c|c|c|c|c|c|c|c|c|c|c|c|}
\hline \multirow[t]{3}{*}{ PA } & \multirow[t]{3}{*}{ Altitude } & \multicolumn{8}{|c|}{ Glossina Species } & \multirow[t]{3}{*}{ No. of Traps } & \multirow[t]{3}{*}{ Tot. Fly Caught } & \multirow[t]{3}{*}{ F/T/D } \\
\hline & & \multicolumn{2}{|c|}{ G. Morsistans } & \multicolumn{2}{|c|}{ G. Pallideps } & \multicolumn{2}{|c|}{ G. Fascipes } & \multicolumn{2}{|c|}{ G. Tachnoids } & & & \\
\hline & & $\mathbf{M}$ & $\mathbf{F}$ & $\mathbf{M}$ & $\mathbf{F}$ & $\mathbf{M}$ & $\mathbf{F}$ & M & $\mathbf{F}$ & & & \\
\hline B. Didesa & $|37|-\mid 386$ & 14 & 17 & 13 & 16 & 23 & 27 & 15 & 14 & 15 & 139 & 4.63 \\
\hline Meta & $1395-1437$ & 36 & 50 & 44 & 74 & 37 & 54 & 172 & 251 & 15 & 423 & 14.1 \\
\hline H. Keku & $14 \mid 7-1437$ & 7 & 23 & 10 & 11 & 33 & 54 & 59 & 107 & 15 & 166 & 5.53 \\
\hline J.Giros & $1395-1482$ & 2 & 5 & 19 & 38 & 1 & 34 & 15 & 18 & 15 & 132 & 4.4 \\
\hline Cafe Arjo & $1460-1528$ & 0 & 0 & 6 & 14 & 17 & 25 & 0 & 0 & 15 & 62 & 2.06 \\
\hline Tuqa & $\mid 472-1648$ & 16 & 26 & 29 & 20 & 26 & 25 & 83 & 78 & 15 & 161 & 5.37 \\
\hline F/T/D & & 0.42 & 0.7 & 0.6 & 0.9 & 0.7 & I.I & 0.6 & 0.7 & 90 & 1083 & 6.01 \\
\hline
\end{tabular}

Abbreviations: F/T/D, fly per trap per day; M, male; F, female; B. Didesa, Badasa Didesa; H. Keku, Hara Keku; J. Giros, Jamo Giros.

G. m. morsitance were collected. From the study PAs, the highest $(14.1 \mathrm{f} / \mathrm{t} / \mathrm{d})$ and the lowest $(2.06 \mathrm{f} / \mathrm{t} / \mathrm{d})$ tsetse catch were in Meta and Caffe Arjo PAs respectively. From a total of 1083 tsetse flies caught, 67.77\% ( $=734)$ were female and $32.22 \%(n=349)$ were male as shown in Table 4. There was a statistically significant difference between both sexes $(\mathrm{P}<0.05)$.

\section{Discussion}

Overall $4.4 \%(n=36)$ prevalence of cattle Trypanosomiasis was recorded in the current study. Relatively similar finding $(2.0 \%)$ of Bovine Trypanosomiasis was reported by Katabazi et al, ${ }^{24}$ from Lira District of Uganda and $4.17 \%$ by Kivali et al, ${ }^{25}$ from Western Kenya. Similarly, Gerem et $\mathrm{al}^{26}$ reported the overall prevalence of $4.5 \%$ of camel trypanosomiasis from Asayita and Dubti area of Afar region. Relatively lower prevalence rate was reported by Girma et $\mathrm{al}^{27}$ who reported $1.3 \%$ in and around Arbaminch area. This finding was relatively lower than reports by Megersa et $\mathrm{al}^{28}$ who indicated $12.24 \%$ from Botor Tolay District and Solomon and Fita, 2011, ${ }^{29}$ who reported 12.41 from Metekel and Awi zones of northwest Ethiopia, Miruk et $\mathrm{al}^{30}$ who reported $20.4 \%$ from Wolayta and Dawuro zones of southern Ethiopia. There are also higher prevalence reports of $41 \%$ and $29 \%$ from other African countries such as Suba and Teso of Kenya ${ }^{31}$ and $20.1 \%$ from Busia district of Western Kenya. ${ }^{32}$

The relatively lower prevalence of the disease in this study may be related to lower tsetse distribution and low animal fly contact. Trypanosome parasite and tsetse fly vector control programs practiced in the area by Bedelle branch NTTICC annually contributed to the lower prevalence rate. The prevalence of cattle trypanosomiasis between PAs was not significantly associated and might be due to the homogeneity in agroecology, vegetation and environment of research areas.

The mean PCV values for each animal sample in the pre intervention survey showed marked statistical difference. This finding was in agreement with a report of Bekele ${ }^{33}$ and Dagnachew et al, ${ }^{34}$ in which parasitaemic animals had mean PCV below 26\%. Likewise, Thrusfield ${ }^{17}$ indicated that the average PCV of parasitologically non-infected animals was significantly higher than those of infected positive animals. Theirfore this disease may significantly lower PCV of infected animals. Though other diseases such as internal parasitosis, tick borne disease and nutritional imbalances contribute to the low PCV values, trypanosome positive (parasitaemic) animals have generally lower mean PCV value than trypanosome negative (aparasitaemic) ones. These factors affect both Trypanosomiasis positive and negative animals. ${ }^{17}$ On the other hand, most of the parasitemic animals in lowland area had good body condition despite having low PCV values.

Packed cell value of animals from all PAs did not show marked difference with majority of animals having comparatively medium PCV value, though animals with low PCV values were also found. The existence of parasitologically negative cattle with PCV values of less than the average value $(25 \%)$ may be due to either inadequacy of detection method $^{20}$ or delayed recovery of anemic condition after current treatment with trypanocidal drugs, or other disease. Presence of positive animals with PCV of greater than $25 \%$ might be due to recent infection of animals.

The higher proportion of T. congolense $(80.55 \%)$ in all PAs in the current study was inconsistent with the report by Katabazi et $\mathrm{al}^{24}$ who reported $81.8 \% T$. congolense 
from the total trypanososomes detected. Similarly, highest prevalence rate of $T$. congolense (59.6\%) was indicated by Megersa et al. ${ }^{28}$ This high prevalence of $T$. Congolense infection in cattle may be because of high serodemes (serological variation) of $T$. congolense as compared to other Trypanosoma species and development of immune response improvement against $T$. vivax by infected animals (Sinshaw et al). ${ }^{9}$

The variation in the prevalence of mixed infections involving different species of trypanosome from different regions and countries is due to the accessibility of the trypanosome species to their specific hosts. The presence of suitable mammalian host remains most likely factor for determining the spread and abundance of trypanosome species (Nimpaye et al). ${ }^{35}$ The presence of other biting flies is playing an important role in the non-cyclical transmission of trypanosomiasis in the study area.

The overall mean catch of tsetse flies was 6.1 flies/trap/ day. This finding was higher than Bekele (2004) reported, $1.35 \mathrm{~F} / \mathrm{D} / \mathrm{T}$ and $0.9 \mathrm{~F} / \mathrm{D} / \mathrm{T}$ in site one and two respectively in two of his study areas and Bekele and Beshir, ${ }^{36}$ who reported 2.42f/t/d. Conversely, Sinshaw ${ }^{9}$ indicated that his trap did not capture any fly. A similar finding was reported from Sayo district by Siyum et al. ${ }^{37}$ This result was lower than in previous work by Megersa et $\mathrm{al}^{28}{ }^{28}$ who reported 11.6 flies/trap/24hrs in Botor Tolay district and by Ragasa and Ababe, ${ }^{38}$ who reported 10.68 flies/trap/day in upper Didessa Valley.

The comparatively low level of tsetse fly and other fly populations in this study may be because of the intervention-like placement of insecticide-impregnated traps, targets, and use of insecticide in the area by NICE Tsetse Fly and trypanosomiasis. Female flies constituted 59.26\% of the catch during the current study. This result is similar to the report of Bekele and Beshir, ${ }^{36}$ who reported $73.2 \%$ of catch were female tsetse. Glossina fuscipes, G. tachinoids, G. pallideps and G.m. submorsitance were the major tsetse fly species caught. This could be due to long life-span of female compared to male flies.

\section{Conclusion and Recommendation}

This study indicated T. congolense, T. brucei, and T. Vivax were responsible for cattle Trypanosomiasis with major clinical sign of anemic state hindering health and production of cattle. The occurrence of the diseases was associated with the tsetse and other biting flies. The disease is still a major constraint in animal health and production, although different control measures have been applied by NICETT. This can be due to inadequate control measures and development of drug resistance by Trypanosome. Therefore, a coordinated control campaign aimed at reducing tsetse fly burden would be necessary to minimize the impact of the disease and further research is needed to investigate effective drugs.

\section{Abbreviations}

BCS, body condition score; NICETT, National Institute for Control and Eradication of Tsetse fly and Trypanosomosis; PCV, packed cell volume.

\section{Data Sharing Statement}

The datasets that support the findings of this study are available from the principal author upon request.

\section{Ethical Approval and Consent to Participate}

All participants were informed about the purpose of this study and signed written legal consent for participation prior to the commencement of the study. Study design involved animals for blood sample and human participants for interview on medicinal plant use. The survey protocol and animal handling ethics were approved by Wollega University School of Veterinary Medicine Ethical Review Board. Support letters were also granted from East Wollega zone, Livestock and Fishery resource office, and the administration Office of East Wollega zone.

\section{Acknowledgments}

The author acknowledges Wollega University and Addis Ababa University.

\section{Author Contributions}

The author contributed to data analysis, drafting or revising the article, gave final approval of the version to be published, agreed to the submitted journal, and agree to be accountable for all aspects of the work.

\section{Funding}

There is no funding to report.

\section{Disclosure}

The author declares no conflicts of interest for this work. 


\section{References}

1. Ayele T, Ephrem D, Elias K, et al. Prevalence of bovine trypanosomosis and its vector density in Daramallo District, South Western Ethiopia. J Vet Adv. 2012;2(6):266-272.

2. Keno $M$ The current situation of tsetse and trypanosomiasis in Ethiopia, ministry of agriculture and rural development, veterinary service department. In Proceedings of 28th Meeting of International Scientific Council for Trypanosomiasis Research and Control (ISCTRC); 2005

3. Stijlemans B, De Baetselier P, Magez S, Van Ginderachter JA, De Trez C. African trypanosomiasis-associated anemia: the contribution of the interplay between parasites and the mononuclear phagocyte system. Front Immunol. 2018;9:218. doi:10.3389/fimmu.2018.00218

4. Radostits OM, Gay C, Blood DC, Hinchclift KW. Veterinary Medicine, a Text Book of the Diseases of Cattle, Sheep, Goats, Pigs and Horses. 10th ed. London: Harcourt Publishers' Ltd; 2007:1564-1569.

5. ToyangNJ, Wanyama J, Nuwanyakpa M, Django S. Mertens H, editor. Ethnoveterinary medicine, a practical approach to the treatment of cattle diseases in sub-SaharanWageningen: Digigrafi; Agromisa; 2007.

6. Guluma K, Debela A, Morka A. Ethnoknowledge of plants used in veterinary practices in Midakegn district, west showa of Oromia region Ethiopia. J Med Plants Stu. 2017;5(5):282-288.

7. Abdeta D, Amante M, Tamiru Y. Survey on Ethno Botany and Medicinal Animals at Sayoand Hawa Gelan Districts of Kelem Wollega Zone, Western Ethiopia. Prev Med. 2020;28(2):21408.

8. Afewerk Y, Clausen PH, Abebe G, Tilahun GA, Dieter M. Appearance of multiple drug resistant trypanosome population village cattle of Metekel district, North West Ethiopia. Livestock Community and Environment. In Proceedings of the 10th Conference of Association of Institute for Tropical Veterinary Medicine; 2001; Copenhagen, Denmark. 1-11.

9. Sinshaw A, Abebe G, Desquesnes M, Yoni W. Biting flies and Trypanosoma vivax infection in three highland districts bordering Lake Tana, Ethiopia. Vet Parasitol. 2006;142(1-2):35-46. doi:10.1016/j.vetpar.2006.06.032

10. Dagnachew S, Mohammed S, Dessie B, Tilahun M, Ayele A, Kefyalew $H$. Bovine and equine trypanosomosis in Northwest Ethiopia: prevalence, density of vectors and control measures. Parasite Epidemiol Control. 2020;11:e00170. doi:10.1016/j.parepi.2020.e00170

11. Langridge WP Tsetse and tryponosomosis survey of Ethiopia Ministry of overseas department UK, 1976 pp: 1-40.

12. Abebe G. Review article: Trypanosomosis in Ethiopia. Ethiop J Biol Sci. 2005;4(1):75-121.

13. Abebe G, Malone JB, Thompson AR. Geospatial forecast model for tsetse transmitted animal Trypanosomiasis in Ethiopia. SINET Ethio J Sci. 2004;27(1):1-8.

14. Uilenberge G, Boyt WP. A Field Guide for Diagnosis, Treatment and Prevention of African Animal Trypanosomosis. Rome: FAO; 1998:43-135.

15. Tafese W, Melaku A, Fentahun T. Prevalence of bovine trypanosomosis and its vectors in two districts of East Wollega Zone, Ethiopia. Onderstepoort J Vet Res. 2012;79(1):1-4. doi:10.4102/ojvr.v79i1.385

16. Thrusfield M. Veterinary Epidemiology. 3rd ed. UK: Black well science Ltd; 2005:233-250.

17. Van den Bossche P, Shumba W, Njagu C, Shereni, W. The distribution of bovine trypanosomosis in Zimbabwe and an evaluation of the value of an anti-trypanosomal antibody detection ELISA as a tool for monitoring the effectiveness of tsetse control operations. Trop Anim Health Prod. 2001;33(5):391-405. doi:10.1023/A:1010591722751

18. Morag GK. Hematology in Veterinary Laboratory Medicine. 2nd ed. London, UK: Blackwell Science; 2002.
19. Murray M, Trial TCM, Stephen LE. Livestock Productivity and Trypanosomosis. Addis Ababa, Ethiopia: ILCA; 1983.

20. Murray M, Murray PK, McIntyre,: WIM. An improved parasitological technique for the diagnosis of African trypanosomosis. Trans $R$ Soc Trop Med Hyg. 1977;71:25-326. doi:10.1016/0035-9203(77)90110-9

21. Brightwell R, Dransfield R, Kyoku C, et al. A new trap for Glossina pallidipes. Trop Pest Manag. 1987;33(2):151-159. doi:10.1080/ 09670878709371136

22. Fisher MS, Say R. Manual of Tropical Veterinary Parasitology. UK: CAB International publication; 1989:100-278.

23. Bekele J, Asmare K, Abebe G. Evaluation of deltamethrin applications in control of tsetse and Trypanosomiasis in southern Rift valley of Ethiopia. Ethiop Vet J. 2008;129:1-9.

24. Katabazi A, Almustapha A, Gift Witto S, Odoki M, Musinguz SP. Prevalence of Trypanosoma congolense and Trypanosoma vivax in Lira District, Uganda. Biomed Res Int. 2021;2021:1-7. doi:10.1155/ 2021/7284042

25. Kivali V, Kiyong'a AN, Fyfe J, Toye P, Fèvre EM, Cook EAJ. Spatial Distribution of Trypanosomes in Cattle from Western Kenya. Front Vet Sci. 2020;7:554. doi:10.3389/fvets.2020.0055

26. Gerem B, Hamid M, Assefa A. Prevalence and associated risk factors of Trypanosoma evansi in Camels in Ethiopia based on parasitological examinations. Vet Med Int. 2020;2020:1-6. doi:10.1155/2020/ 6172560

27. Girma K, Meseret T, Tilahun Z, et al. Prevalence of bovine trypanosomosis, its vector density and distribution in and around Arbaminch, Gamogofa Zone, Ethiopia. Acta Parasitologica Globalis. 2014;5 (3):169-176.

28. Megersa L, Feyisa B, Dereje A, Behablom M. Prevalence of bovine trypanosomosis and apparent density of tsetse fly in Botor Tolay District, Jimma Zone, Ethiopia. Biomed J Sci Tech Res. 2019;1:8.

29. Solomon M, Fitta G. Survey on bovine trypanosomosis and its vector in Metekel and Awi zones of northwest Ethiopia. Acta Tropica. 2011;117(2):146-151.

30. Miruk A, Hagos A, Yacob HT, Asnake F, Basu AK. Prevalence of bovine trypanosomosis and trypanocidal drug sensitivity studies on Trypanosoma congolense in Wolyta and Dawero zones of southern Ethiopia. Vet Parasitol. 2008;152:141-147. doi:10.1016/j. vetpar.2007.12.007

31. Thumbi SM, Jung'a JO, Mosi RO, McOdimba FA. Spatial distribution of African Animal Trypanosomiasis in Suba and Teso districts in Western Kenya. BMC Res Notes. 2010;3:6. doi:10.1186/1756-0500-3-6

32. Von Wissmann B, Machila N, Picozzi K, et al. Factors associated with acquisition of human infective and animal infective trypanosome infections in domestic livestock in Western Kenya. PLoS Negl Trop Dis. 2011;5:e941. doi:10.1371/journal.pntd.0000941

33. Bekele D. Epidemiology of Bovine Trypanosomiasis in selected sites of southern rift valley of Ethiopia. Ethiop Vet J. 2004;111:18-24.

34. Dagnachew S, Arun K, Abebe G. Assessment of trypanocidal drug resistance in cattle of the Abay (Blue Nile) basin areas, north western Ethiopia. Ethiop Vet J. 2006;2(1):45-63.

35. Nimpaye H, Njiokou F, Njine T, et al. Trypanosoma vivax, T. congolense "forest type" and T. simiae: prevalence in domestic animals of sleeping sickness foci of Cameroon. Parasite. 2011;18 (2):171-179. doi:10.1051/parasite/2011182171

36. Bekele D, Beshir A. Host related risk factors of bovine trypanosomosis and vector density in Halu District of Ilubabor Zone, West Ethiopia. Vet Med Open J. 2021;6(1):32-38. doi:10.17140/VMOJ6-156

37. Siyum G, Tadele K, Zelalem A, Benti D. Epidemiological survey of bovine trypanosomosis in Sayo District of Kellem Wollega Zone, Western Ethiopia. Am Eurasian J Agric Environ Sci. 2014;9 (3):67-75. doi:10.5829/idosi.aejsr.2014.9.3.85199

38. Regassa F, Abebe G. Current epidemiological situation of bovine trypanosomosis in Limu Shay tsetse controlled area of Upper Didessa Valley. Ethiop Vet J. 2009;13(2):19-23. 


\section{Publish your work in this journal}

Veterinary Medicine: Research and Reports is an international, peerreviewed, open access journal publishing original research, case reports, editorials, reviews and commentaries on all areas of veterinary medicine. The manuscript management system is completely online

Submit your manuscript here: http://www.dovepress.com/veterinary-medicine-research-and-reports-journal and includes a very quick and fair peer-review system. Visit http://www.dovepress.com/testimonials.php to read real quotes from published authors. 